\title{
O erro médico e a violação às normas e prescriçôes em saúde: uma discussão teórica na área de segurança do paciente
}

\section{| ${ }^{1}$ Nadia Bomfim do Nascimento, ${ }^{2}$ Cláudia Maria de Rezende Travassos |}

Resumo: Em 1999, o relatório do Instituto de Medicina (IOM), ao apontar que há significativa ocorrência de eventos adversos e que mais da metade dessas ocorrências eram ocasionadas por erro médico, suscitou inúmeras ações e pesquisas na área de Segurança do Paciente. As infecções relacionadas à assistência à saúde (IRAS), um dos problemas enfrentados na área, é alvo de pesquisas que intentam criar procedimentos e estratégias no sentido de prevenir tais eventos. A higienização de mãos, por ser a medida mais simples no controle das IRAS e, paradoxalmente, a que possui mais baixo índice de adesão entre os médicos, é alvo de inúmeros programas e campanhas. A necessidade de reversão do quadro apontado tem gerado extensa literatura que, entre outros, identifica barreiras e fatores de risco para a baixa adesão a normas e procedimentos de higienização de mãos, como também busca compreender os aspectos comportamentais envolvidos. Este artigo apresenta alguns modelos teóricos explicativos voltados para a compreensão da dinâmica comportamental que envolve a consecução do erro e da violação e realiza uma análise com possibilidades à depreensão do processo. Por fim, considera-se que os modelos explicativos apresentados, conjuntamente, trazem contribuições passíveis de aplicação na prática e que a identificação e compreensão dos mecanismos de defesa coletivos levariam aos fatores que se encontram em jogo na baixa adesão aos procedimentos de higienização de mãos por parte dos médicos, a despeito das evidências existentes.

> Palavras-chave: segurança do paciente, erro médico, violação.
1 Doutoranda em Saúde Pública, Escola Nacional de Saúde Pública Sérgio Arouca (ENSP - FIOCRUZ).

Endereço eletrônico:

nadiabomfim@uol.com.br

${ }^{2}$ Médica, Pesquisadora Titular do Instituto de Comunicação e Informação Científica e Tecnológica (ICICT - FIOCRUZ).
Recebido em: 08/07/2009. Aprovado em: 20/04/2010. 
Nos últimos vinte anos, as organizações e agências internacionais de saúde têm evidenciado a necessidade de desenvolver dispositivos para a melhoria da segurança do paciente. Ao longo desse período, desenvolveram um número significativo de estratégias voltadas para melhorar a qualidade do cuidado à saúde e, consequentemente, minorar os riscos inerentes a esses cuidados de saúde oferecidos.

A segurança do paciente, uma importante dimensão da qualidade em saúde, se tornou foco de atenção a partir do relatório apresentado pelo Instituto de Medicina há aproximadamente dez anos - To err is human (KOHN; KORRIGAN; DONALDSON, 2000) -, que apontou a alta frequência de eventos adversos resultantes do cuidado hospitalar, ou seja, incidentes que resultavam em dano para o paciente, e que mais da metade dos casos eram ocasionados por erros médicos. Vários fatores foram inicialmente apontados como fomentadores das condições de insegurança do paciente, dentre eles, o silêncio que cerca a questão do erro médico. Apesar dos esforços despendidos até o momento na busca da compreensão e criação de estratégias que contemplem a questão, poucas respostas efetivas foram obtidas e isso se deve, em parte, à complexidade do tema, como também à complexa natureza do cuidado em saúde.

"O cuidado em saúde tem sido caracterizado como resultante de um complexo sistema sócio-técnico, no qual papéis e responsabilidades geralmente desafiam definiçõos formais tais como as descriçõos das atividades do trabalho" (COHEN et al., 2007, p. 312). Nesse sistema, erros podem ocorrer em função do aspecto exploratório inerente ao permanente processo de aprendizagem associado à execução do trabalho clínico, como nos sugerem Cohen e colaboradores (007). A distinção entre erro e violação tem sido suscitada por alguns autores (COHEN et al., 2007; MERRY; SEDDON, 2006) como um caminho para a compreensão dos processos envolvidos na ocorrência do erro. A identificação e compreensão dos atos de violação possibilitariam a precoce identificação de situações vulneráveis à ocorrência de erro, já que a violação de normas prescritas é assumida como a etapa inicial de um processo de progressão que culmina na ocorrência de erro médico (CHEN et al., 2007).

$\mathrm{Na}$ área de Segurança do Paciente, as infecções relacionadas à assistência à saúde (IRAS) representam um problema para o qual convergem pesquisas, 
procedimentos e estratégias, que abrangem desde a criação de insumos e tecnologias de alta complexidade até o treinamento dos recursos humanos e o envolvimento dos pacientes. Duas questôes importantes resultam desse esforço. A primeira é o consenso de que a higienização de mãos [hand hygiene] (GUIDELNES, 2006) é uma medida simples, de baixo custo e baixa complexidade e, portanto, um dos pilares na prevenção e controle da infecção hospitalar. A segunda é o reconhecimento, apontado por diversos estudos, da baixa adesão dos profissionais de saúde à prática de higienização das mãos, apontada por diversos estudos (MORET et al., 2004; PITTET, 2001a; PITTET, 2001b; HUGONNET; PITTET, 2000). A baixa adesão à higienização das mãos constitui uma violação às normas prescritas e nos parece ser um fenômeno e condição exemplar a ser investigado com vistas à prevenção de erro.

Os estudos sobre a baixa adesão aos procedimentos de higienização de mãos apontam vários fatores que afetam a execução do procedimento preconizado e, consequentemente, a aderência: produtos abrasivos e/ou inadequados que causam irritação na pele; ausência de material para realização da higienização próxima aos locais de atendimento dos pacientes; a falta de tempo para a realização do procedimento, devido ao excesso de carga de trabalho; a equipe reduzida, entre outros (PITTET, 2001b; HUGONNET; PITTET, 2000; BEGGS et al., 2006; CHALMERS, 2006). Foram também identificados como preditores de baixa aderência aos procedimentos de higienização das mãos: a categoria profissional, o local do hospital, o horário do dia ou semana, o tipo e a intensidade do cuidado dispensado ao paciente (MORET et al., 2004; PITTET, 2001a; PITTET, 2001b; HUGONNET; PITTET, 2000). Os médicos foram apontados como os profissionais de saúde que apresentaram a menor adesão à higienização das mãos, dentre aqueles que executam suas atividades no ambiente hospitalar. Moret e colaboradores (2004) destacam que esse comportamento tende a influenciar os demais componentes da equipe, tendo em vista o papel modelar que o médico ocupa entre os profissionais de saúde. A baixa adesão do médico e seu papel dentro da equipe de trabalho ratificam a necessidade de investigação sobre a questão da baixa adesão à higienização como fator de prevenção à ocorrência das IRAS; de forma mais ampla, possibilita a tentativa de se compreender o processo que envolve a dinâmica do comportamento relativo à violação as normas e procedimentos preconizados, que pode ocorrer tanto nos procedimentos mais simples, como na higienização de mãos, até os que demandam maior tecnologia e complexidade. 
Algumas teorias sobre o erro foram propostas na tentativa de compreender e lidar com o fenômeno. James Reason (2003), através da psicologia cognitiva, buscou a compreensão do comportamento humano na ocorrência do erro e seus achados vêm sendo utilizados em diversas áreas onde o processo de trabalho humano se realiza. Runciman e colaboradores (2007) tomam como base a teoria proposta por Reason para entender como esse processo ocorre na área de saúde, tendo em vista a especificidade e complexidade a que está sujeita. Christophe Dejours (1987, 1999, 2005 e 2007) volta sua atenção para a dimensão humana do trabalho e o microcosmo onde ela se dá. Parte do princípio de que o trabalho, na sua execução cotidiana, está intrinsecamente ligado ao fracasso e que é necessário criar condiçôes sociais e psicoafetivas favoráveis para que o indivíduo possa enfrentar e se sobrepor às situações imprevistas.

Com o intuito de alcançarmos maior compreensão sobre o tema e com a perspectiva de intervenção na realidade laboral, a seguir exporemos de forma sucinta o trabalho dos autores acima mencionados, seguida de breve discussão.

\section{Errar é humano}

Os conceitos fator humano e, posteriormente, erro humano, foram amplamente utilizados pelo psicólogo cognitivo James Reason, professor de psicologia da Universidade de Manchester e membro da Sociedade Britânica de Psicologia, nos estudos por ele desenvolvidos na busca do entendimento dos mecanismos do comportamento humano na ocorrência do erro. Esses estudos e subsequentes publicações foram inicialmente direcionados à área da aviação, posteriormente às indústrias de grande porte e, mais recentemente, à área de saúde. A Segurança do Paciente, definida pela Organização Mundial de Saúde (OMS) como a ausência de dano potencial ou desnecessário para o paciente associado aos cuidados em saúde, e a capacidade de adaptação das instituições de saúde em relação aos riscos humanos e operacionais inerentes ao processo de trabalho, são o foco central desses estudos, que têm como objetivo criar instrumentos para manejo do ato inseguro. Tornar-se resiliente, objetivo dos sistemas e organizaçôes de alta complexidade, tal qual o sistema de saúde é, portanto, torná-lo tão robusto e praticável em face de situações que envolvem riscos humanos e operacionais e, consequentemente, a ocorrência de erro (REASON, 2003). Conter os efeitos danosos emergentes dessa ocorrência e mesmo assim atingir os objetivos propostos encerram em si um 
trabalho com múltiplos objetivos, já que levam em conta as ações do indivíduo, da equipe, o local de trabalho e a empresa como um todo.

A teoria sobre o erro humano, produto da extensa pesquisa realizada sobre o tema, foi apresentada em livro editado no ano 1990 - Human error. Nele, James Reason tem como proposta apresentar uma teoria que se volte para uma análise mais profunda da questão, ultrapassando a mera descrição de princípios gerais sobre a ocorrência e tipos de erros. Reason tem como público-alvo não só os psicólogos cognitivos, mas também os engenheiros, profissionais na área de segurança e estudantes. Objetiva a transmissão e o fomento da discussão no nível teórico, como também a aplicação prática de seus achados. A discussão teórica busca o avanço do conhecimento a respeito dos processos em que o erro humano se engendra, e a aplicação prática tem o propósito de eliminar ou conter os efeitos adversos decorrentes desse erro.

Reason introduz o tema com uma discussão sobre a natureza do erro. Nessa discussão, aponta que as noções de intenção e erro são inseparáveis, ou seja, o termo erro só pode ser aplicado às ações intencionais, já que os tipos de erro dependem de duas espécies de falhas: (i) falhas na execução, ou seja, as falhas nas ações que caminham de acordo com a intenção pretendida - deslizes e lapsos [slips and lapses] e (ii) falhas no planejamento, ou seja, as falhas das ações intencionais para alcançar os resultados desejados - enganos [mistakes]. Para a discriminação e categorização do erro numa ação realizada, Reason utiliza o método indutivo de inquirição através das três questōes seguintes: (1) "existiu uma prévia intenção para agir?”; (2) "as açôes procederam de acordo com o plano?”; (3) "as açôes alcançaram o fim desejado?”. As duas últimas questôes, segundo o autor, possibilitam a construção de uma taxonomia do erro psicologicamente significativa.

Reason propõe uma definição operacional [working definition] sobre erro, em função de sua utilidade na composição das características psicológicas essenciais do fenômeno. "O erro será tido como um termo geral que abrange todas aquelas ocasiōes em que uma sequência traçada de atividades mentais ou físicas falha em alcançar o resultado esperado e quando estas falhas não podem ser atribuídas à intervenção do acaso" (REASON, 2003, p. 9). A distinção entre as ações que não ocorrem conforme planejadas e aquelas devidas à inadequação do plano dentro da mesma sequência de execução de uma determinada ação ou comportamento, como vimos acima, aponta para duas subsequentes definições operacionais, 
a saber: (i) deslize [slip] (e) lapso [lapse], que são ambos [operacionalmente] definidos como "erros que resultam de alguma falha na execução e/ou no estágio de armazenagem de uma sequência de ação, independentemente se o plano que os guia é ou não adequado para alcançar o objetivo" (REASON J, 2003, p. 9). $\mathrm{O}$ deslize está mais diretamente relacionado a ações observáveis que se realizam fora do plano prescrito. Já o lapso é geralmente relacionado a formas de erros mais encobertas e que não se manifestam necessariamente sobre a forma de comportamento, como por exemplo, falha de memória; (ii) engano [mistake], que é tida como "deficiência ou falha no processo de julgamento ou inferência envolvido na seleção de um objetivo ou na especificação dos meios para alcançálo, independente das açôes dirigidas ao esquema de decisão ocorrer ou não de acordo com o planejado" (REASON J, 2003, p. 9). Esta última definição é mais sutil e complexa, portanto com maior dificuldade de detecção. A distinção entre as definições operacionais deslize [slip] (e) lapso [lapse] - falha na execução, e engano [mistake] - falha no planejamento, fazem parte da classificação de erro no desempenho humano estruturada por J. Rasmussen (1986). Essa classificação foi utilizada por Reason como base para seu sistema classificatório, que segundo o mesmo não era suficiente para apreender todos os tipos básicos de erros.

As definições operacionais acima assinaladas são as bases, utilizadas por Reason, para a identificação e o delineamento das diversas categorias do erro: classificação, tipos e formas. Desempenho correto e erro sistemático são os dois lados ou manifestações do mesmo balancete cognitivo [cognitive sheet], é o que assinala o autor. Os erros não são tão abundantes e variáveis como pode sugerir uma avaliação menos apurada. Eles também tendem a ter número limitado de formas quando confrontados com suas possíveis variações. Os erros apresentam uma roupagem similar ao longo de um amplo espectro de atividades mentais. Portanto, é possível identificar formas comparáveis de erros nas atividades da ação, fala, percepção, recordação, reconhecimento, julgamento, solução de problemas, decisão, formação de conceitos e similares.

Os mecanismos básicos e os processos que geram recorrentes formas de uma variada gama ou tipos de erros são descritos por Reason sob a forma do sistema de modelos gerais de erros / SMGE [generic error-modelling system / GEMS] (quadro 1), que têm como objetivo precípuo delimitar as origens dos tipos básicos de erro humano, apresentar um modelo integrado e dinâmico dos mecanismos 


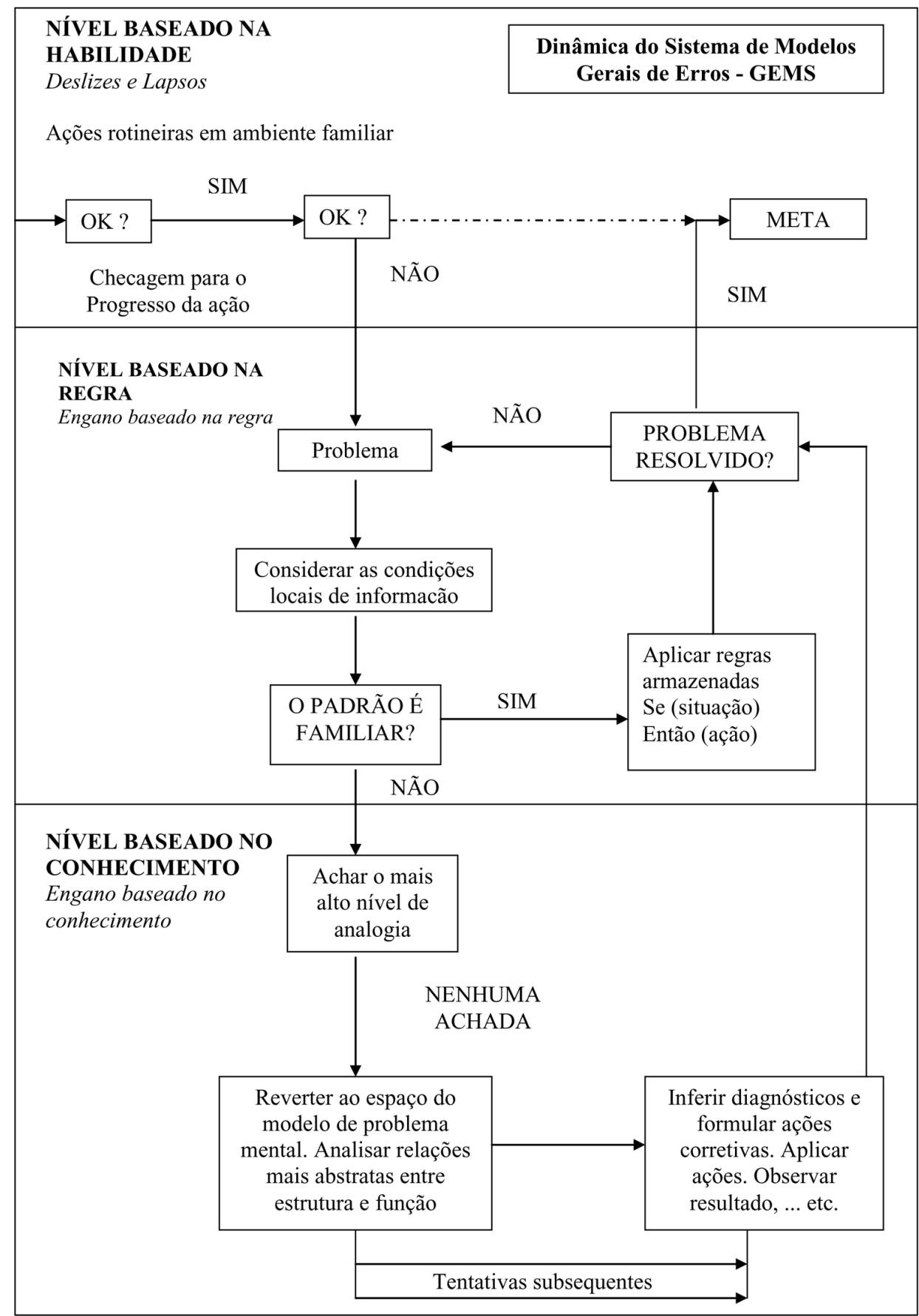

Fonte: Reason. Human Error (2003, p. 64). 
operativos do erro, e especificamente, procurar integrar as duas áreas aparentemente distintas de erros: (i) deslizes e lapsos [slips and lapses]; e (ii) enganos [mistakes]. Esse modelo permite a identificação e a descrição de três tipos/mecanismos básicos de erros: 1) deslize e lapso com base na habilidade [skill-based slips and lapses]; 2) engano com base nas normas [ruled-based mistake]; 3) engano com base no conhecimento [knowledge-based mistake]. E mostra também como a detecção da existência de um problema na execução de uma determinada tarefa pode ser apontada como um referencial na consecução do erro, tendo em vista que os deslizes e lapsos com base na habilidade precedem a detecção do problema e são geralmente categorizados como falhas de monitoramento. Os enganos baseados na norma ou no conhecimento se enquadram como falhas que ocorrem imediatamente após a detecção do problema e são considerados como falhas gerais na resolução de problemas.

$\mathrm{O}$ deslize e lapso com base na habilidade, como vistos anteriormente, são geralmente atribuídos a falhas no monitoramento de uma ação rotineira ou contínua devido à desatenção ou a excessiva concentração, onde é feita uma checagem atenta em um ponto inapropriado de automatizada sequência de açôes. Ambas podem ser denominadas como falha no modo de controle, pois os erros ocorrem em função de estarem num modo de controle errado em referência as demandas da tarefa. Este nível - nível baseado na habilidade - está relacionado ao desempenho de atividades altamente rotineiras em ambientes familiares.

$\mathrm{O}$ engano com base nas normas e o engano com base no conhecimento estão associados à resolução de problemas, tendo em vista que um problema, segundo definição do autor, é uma situação que requer uma revisão de uma ação corrente programada que tem por base normas e conhecimentos relativos à sua execução. Somente quando há falha no modelo semiautomático relacionado aos procedimentos de combinação de padrões e de aplicação de regras para a resolução de problemas, ou seja, falha na execução de ações ou atividades rotineiras, é que uma forma mais laboriosa de realizar inferências, a partir do modelo mental de resolução de problemas baseado no conhecimento, é ativada.

O nivel baseado nas regras, onde os enganos baseados nas regras ocorrem, é demandado quando se detecta um desvio, a partir da checagem de atenção, em relação ao que foi planejado para a consecução de uma determinada atividade. Quando os desvios são menores e as regras apropriadas para a resolução dos problemas são encontradas e aplicadas, há o retorno ao nivel baseado em habilidade. 
Quando os desvios e/ou problemas são maiores, o ciclo que ocorre dentro deste nível deve ser repetido várias vezes.

Um aspecto central deste modelo, no que diz respeito às normas, é que elas são estabelecidas segundo hierarquias de falha [default hierarquies] em relação ao seu conteúdo, sendo que as normas que possuem representações mais gerais dos objetos ou eventos se situam nos níveis mais altos da hierarquia, e as mais específicas e que contemplam as exceções se situam em níveis hierárquicos mais baixos. A adição de normas cada vez mais específicas aumenta a complexidade e adaptabilidade do modelo como um todo e a possibilidade do surgimento de erro na sua aplicação. $\mathrm{O}$ engano com base nas normas se relaciona então, a duas outras categorias: a má aplicação de boas normas [misapplication of goog rules] e a aplicação de más normas [application of bad rules]. No caso da má aplicação de boas normas, tendo como definição de boa norma ser aquela com comprovada utilidade em uma particular situação (REASON, 2003, p. 75), observa-se que essas normas, embora perfeitamente adequadas a certas circunstâncias, podem ser aplicadas de forma inadequada em situaçóes que possuem características comuns, mas que também possuam elementos ou circunstâncias que demandam outro tipo de ação. Em função desta condição, o autor aponta que vários fatores concorrem na aplicação errada das normas de nível mais geral ou de normas "forte-mas-errada" [strong-but-wrong], ou seja, onde a ação errada é mais uma conservação de práticas passadas do que a demanda da circunstância corrente e a força é determinada pela relativa frequência de execução bem sucedida de referida ação. Reason (2003, p. 65) aponta que "os seres humanos têm uma forte tendência de buscar e achar soluçooes previamente estabelecidas no nível baseado nas normas antes de recorrer a uma ação de maior esforço no nível baseado no conhecimento, mesmo onde esta última é demandada a princípio".

A aplicação de más normas pode emergir, de uma forma geral, da deficiência na decodificação do problema, onde numa particular situação não se consegue decodificála de forma alguma ou quando há deturpação dos componentes da norma. Ela pode também emergir da deficiência das açóes utilizadas a partir de referida norma usada como parâmetro, ocasionando respostas inadequadas e/ou ineficientes em relação ao resultado esperado ou em conformidade com norma utilizada.

Quando todo o repertório de normas utilizadas na resolução de um determinado problema não traz solução adequada para enfrentá-lo, inicia- 
se, então, o processo de formulação e experimentação de várias possibilidades remediadoras no nivel baseado no conhecimento do SMGE. Reason menciona que a passagem do nivel baseado nas normas para o nivel baseado no conhecimento possui fatores determinantes menos distintos e que os fatores emocionais provavelmente desempenham um aspecto importante. Recorrer a um esquema de funcionamento que exige maior esforço poderá depender da combinação entre incerteza (subjetiva) e preocupação ocasionada pelo reconhecimento de que sucessivas tentativas de soluções baseadas na utilização das normas não foram bem-sucedidas. Por outro lado, paralelamente ao esforço de formulação de possibilidades remediadoras, há a tendência de continuar buscando, mesmo que inconscientemente, por ações análogas previamente armazenadas que possam trazer soluções ao problema, numa tentativa de retornar ao nivel baseado nas normas. A circulação entre esses dois níveis pode ocorrer repetidas vezes enquanto várias similaridades são exploradas.

O engano com base no conhecimento tem raízes em dois aspectos da cognição humana: (i) na racionalidade limitada [bounded rationality], ou seja, processo de raciocínio consciente lento, sequencial, laborioso e de recursos limitados frente à resolução dos problemas que são apresentados; (ii) no fato de que o conhecimento relevante para a solução dos problemas é geralmente incompleto e impreciso, isto é, insuficiente disposição para localizar um único fator que aglutine o conhecimento e a incompletude do conhecimento. Para lidar com esse tipo de engano, se faz necessário primeiramente reconhecer com que tipo de configuração de problema nos deparamos, ou seja, qual o "montante de pistas, indicadores, sinais, sintomas e condições profissionais que estão imediatamente disponíveis para quem avalia o problema e sobre os quais trabalha para alcançar uma solução" (REASON, 2003, p. 87). Reason aponta três tipos de configuraçôes de problemas: (i) configuraçôes estáticas [static configurations], nas quais as características do problema permanecem fixas independentemente das ações daqueles que se debruçam para resolvê-las, como por exemplo, a Lei de Responsabilidade Fiscal, no que diz respeito ao montante de gastos possíveis; (ii) configuraçôes de dinâmica reativa [reactive-dynamic configurations], onde as configurações do problema mudam como consequência direta das ações daqueles que intervêm; o que pode ser observado na forma de enfrentamento de problemas cotidianos pelo gestor hospitalar que varia segundo estilo pessoal, formação acadêmica e orientação 
política; iii) configuraçôes dinâmicas-múltiplas [multiple-dynamic configurations], neste caso, as configurações do problema podem mudar tanto em função das ações empreendidas por aqueles que buscam resolve-la, quanto paralelamente a fatores situacionais ou do sistema que acontecem espontaneamente. Reason chama atenção para uma importante distinção neste tipo de configuração, pois ela pode ocorrer de tal modo que as variações do problema podem se originar de fontes limitadas e conhecidas como no caso de um gestor de instituição hospitalar pública cuja orientação política entra em conflito com a orientação político-administrativa do Secretário de Saúde de seu município. Mas também pode ser de natureza mais complexa, ao se originar de fontes muito diversas, em que algumas delas são pouco conhecidas ou não são passíveis de serem controlada, como ocorre com a premência de reestruturação do sistema de navegação aéreo brasileiro após o acidente entre o avião de companhia comercial aérea e a aeronave de pequeno porte.

O reconhecimento dessas diferenças requer estratégias diferenciadas e, paralelamente, trazem à tona diferentes formas de patologias de solução de problemas, ou seja, erros de raciocínio na solução dos problemas, que em última instância geram enganos com base no conhecimento. Seleção inapropriada de informação em função da tarefa, confiança excessiva na avaliação da correção ou precisão do próprio conhecimento, simplificação na relação de causa e efeito na análise do problema ocasionando subestimação de irregularidades futuras, dentre outras, são algumas dessas patologias.

O sistema cognitivo como um todo tende, por ocasião da existência de conflitos entre ações, atividades ou estruturas de conhecimento inespecificas (ou ainda não reconhecida dentro do sistema), selecionar apropriadamente conforme o contexto, em favor das respostas que se apresentam em maior frequência. A inespecificidade cognitiva [cognitive underspecification], conceito introduzido pelo autor em função deste fenômeno, e que diz respeito às operações cognitivas cujas características não são descritas ou delineadas de forma rigorosa, minuciosa e precisa, dá origem a diversos tipos de erros.

Os erros provenientes da inespecificidade cognitiva se conformam primariamente a partir de dois fatores: o de similaridade e o de frequência. Há um processo de correção automática, em que estruturas de conhecimentos são acionadas e o produto desta ação é levado para a consciência através de pensamentos, imagens, palavras, e aí então para o ambiente do indivíduo através das ações, falas ou 
gestos. Neste automatismo, há dois processos envolvidos, o de combinação por similaridade [similarity matching] e o do jogo de frequência [frequency-gambling]. $\mathrm{O}$ primeiro processo se dá quando atributos particulares do conhecimento são combinados, à medida que são acionados, tomando por base a similaridade. No segundo processo, a alta frequência é a resposta ao conflito das escolhas para combinação das estruturas de conhecimento. Ambos, mas marcadamente o último, são processos que se tornam proeminentes à medida que as operações cognitivas se apresentam insuficientemente especificadas. A inespecificidade cognitiva, em última instância, tem suas origens na insuficiente disposição em localizar um único fator que congregue o conhecimento e a incompletude do conhecimento e permeia, de uma forma ou de outra, todas as ações que estejam relacionadas à solução de problemas dentro do sistema cognitivo.

Runciman e colaboradores (2007) destacam a complexidade e especificidade do sistema de saúde. A especificidade reside no fato dos profissionais de saúde lidar invariavelmente com grande diversidade de tarefas e meios para executá-las; em ter como clientela pessoas vulneráveis o que aumenta os riscos da ocorrência de danos devido a atos inseguros e, por último, a condição de que a maioria das ações executadas em áreas críticas de segurança é realizada por mãos humanas, o que gera diminuição na padronização das atividades e incertezas. Para Runciman et al. (2007, p. 111),

é vital distinguir-se os erros, cuja origem está na evolução humana e sua prevenção na capacidade do sistema de evitar sua ocorrência; e violações, cuja origem está no comportamento e na cultura e cuja prevenção está na mudança do comportamento e na apreensão do desenho do sistema.

Runciman et al., ao focarem os cuidados de saúde, propõem uma extensão do sistema de modelos gerais de erros/SMGE descrito por Reason, com o objetivo de ampliar operacionalmente a capacidade de planejamento e execução de estratégias corretivas para lidar com o erro. O sistema de classificação de erro proposto por Runciman e colaboradores amplia e sistematiza os três tipos básicos de erros descritos por Reason - erros baseados no conhecimento, baseado nas normas e baseado na habilidade (deslizes e lapsos) -, no qual o mesmo tipo de erro pode provir de bases cognitivas diferentes. Os tipos de erros propostos são: (i) erros de informação [errors in information]; (ii) erros na aquisição de conhecimento [errors in acquisition of knowledge]; (iii) erros de percepção [errors in perception]; (iv) erros de combinação [errors in matching]; (v) erros no armazenamento do 
conhecimento como esquema [errors in knowledge stores as schemata]; (vi) erros no armazenamento do conhecimento como norma [errors in knowledge stores as rules]; (vii) erros baseados na habilidade - descuido e lapso [skill based errors - slips and lapses]; (viii) erros na escolha de regras [errors in choice of rules]; (ix) erros técnicos [technical errors]; (x) erros deliberados [deliberative errors]. Os conceitos de erro e violação e suas respectivas aplicações possuem definições distintas dentro dos sistemas classificatórios propostos por Reason e Runciman.

Para Runciman e colaboradores, violaçôes diferem de erros pelo fato de os primeiros envolverem um elemento de escolha e geralmente implicarem ações que fogem ao prescrito nas normas, ações estas que reconhecidamente incorrem em risco. Também ressaltam que a violação não se aplica a situações onde haja intenção de dano. Reason, por sua vez, apresenta duas diferentes definições que podem ser conjugadas. A primeira delas diz que "violação é um desvio deliberado, mas não necessariamente repreensível, de procedimentos operacionais seguros, padrões ou normas" (RUNCIMAN et al., 2007, p. 122). A segunda definição, à qual Runciman et al. se contrapõem de forma mais clara, afirma que "o limite entre erro e violação não é tão rigoroso e palpável, nem em termos conceituais nem dentro da sequência de ocorrência de um acidente em particular" (RUNCIMAN et al., 2007, p. 122). Runciman e colaboradores, ao fazerem distinção entre violação e erro, propóem uma classificação especifica para as violações, da qual destacamos o tipo violação de rotinas. Esse tipo de violação, segundo os autores, ocorre na execução das atividades diárias na maioria dos ambientes de trabalho, com o objetivo de "aparar as arestas" para se levar a cabo uma determinada tarefa proposta. A baixa adesão à higienização de mãos por parte dos profissionais de saúde - falha na lavagem de mãos entre o contato sucessivo com os pacientes, entre outros - é trazido como um exemplo paradigmático, e que não tem sua incidência reduzida apesar de as evidências apontarem que a utilização deste procedimento reduz significativamente o risco de infecção hospitalar (RUNCIMAN et al., 2007). Os autores argumentam em favor da distinção entre esses dois tipos de comportamento - violação e erro -, que a ocorrência diária da violação também a diferencia do erro, já que tanto para ele quanto para James Reason, este último só ocorre excepcionalmente. Acrescenta:

a existência de escolha em violaçóes rotineiras pode existir apenas nas primeiras vezes em que a violação é cometida. Apesar disso é geralmente possível mudar o comportamento com relação à violação através de uma decisão de parar de violar. 
Quais seriam os fatores associados ao ambiente, de um lado, e aos indivíduos envolvidos na execução da tarefa, de outro, que fomentariam a escolha inicial que levaria ao afastamento da execução das tarefas conforme a prescrição das normas? E consequentemente, o que as manteria nesta direção?

James Reason, como assinalado anteriormente, tem uma genuína preocupação com a aplicação prática da teoria e conceitos por ele formulados no que diz respeito à detecção e à correção do erro. Apesar da insuficiente compreensão a respeito desses mecanismos, o autor sustenta que há um vasto campo para argumentação e aprofundamento sobre o tema e aponta algumas hipóteses: (i) o processo da atenção [attentional process] envolvido no monitoramento da execução de um plano de ação é razoavelmente bem-sucedido na detecção de desvios não intencionais, mas quando a construção deste plano é de um nível mais elaborado, há uma relativa insensibilidade ao real ou potencial extravio de algumas etapas adequadas em direção ao objetivo desejado; (ii) a relativa eficiência dos mecanismos de detecção de erro depende decisivamente da mediação e adequação da retroalimentação de informaçãao e a qualidade desta última sofre crescente degradação a medida que o plano de ação alcança níveis mais elaborados de controle.

Reason (2000) propóe duas formas de abordar o erro - a abordagem do sujeito [person approach] e abordagem do sistema [system approach]. A primeira se detém nos atos inseguros dos indivíduos que trabalham na ponta, isto é, nos erros e violação de procedimentos adotados por pilotos de avião, controladores de vôo, médicos, enfermeiras, cirurgiōes, e similares a partir de um processo mental fora do padrão, tais como: esquecimento, desatenção, descuidado, motivação pobre, negligência e imprudência. A abordagem do sistema tem como premissa básica a falibilidade dos seres humanos e, portanto, erros são esperados mesmo nas organizações de excelência. Essa abordagem não enfatiza a perversidade humana nem a culpabilização e a responsabilização do indivíduo como única causa do erro. Aspectos morais também são colocados em segundo plano. Nesse caso, assume-se a premissa de que não se pode mudar a natureza humana, mas que é possível mudar as condições em que os indivíduos trabalham. Os sistemas de defesa são o eixo desta abordagem. Na ocorrência do erro, a questão importante é identificar-se como e porque as defesas falharam. 
Os conceitos de erro ativo [active error] e erro latente [latent error] (REASON, 2003 ; 2000) são utilizados pelo autor para justificar a forma de manejo de erro por ele defendida, a abordagem do sistema [system approach]. Os erros ativos são atos inseguros cometidos por uma pessoa que está em direto contato com o sistema e pode assumir variadas formas - deslize e lapso com base na habilidade, enganos com base nas normas, enganos com base no conhecimento ou violaçôes. $\mathrm{O}$ erro latente é um ato ou ação evitável existente dentro do sistema e surge a partir de decisões feitas por analistas, gerentes e pelo alto nível gerencial.

James Reason (2000) propõe o "modelo do queijo suíço no sistema de acidentes" (figura 1), que se adequa especialmente aos sistemas de alta tecnologia por eles terem várias camadas defensivas: algumas são construídas como alarmes, umas são focadas nos indivíduos que trabalham nas ações finalistas ou de ponta (cirurgiôes, pilotos e etc.) e outras dependem de procedimentos e dos controles administrativos. Suas funções são proteger potenciais vítimas e situações do risco casual. Na prática, as barreiras defensivas são como fatias de queijo suíço, com muitos furos. Somente quando os furos, nas várias camadas defensivas, estão momentaneamente dispostos em uma mesma linha, permite-se que a trajetória do acidente venha a ocorrer.

Figura 1 - Modelo do Queijo Suíço

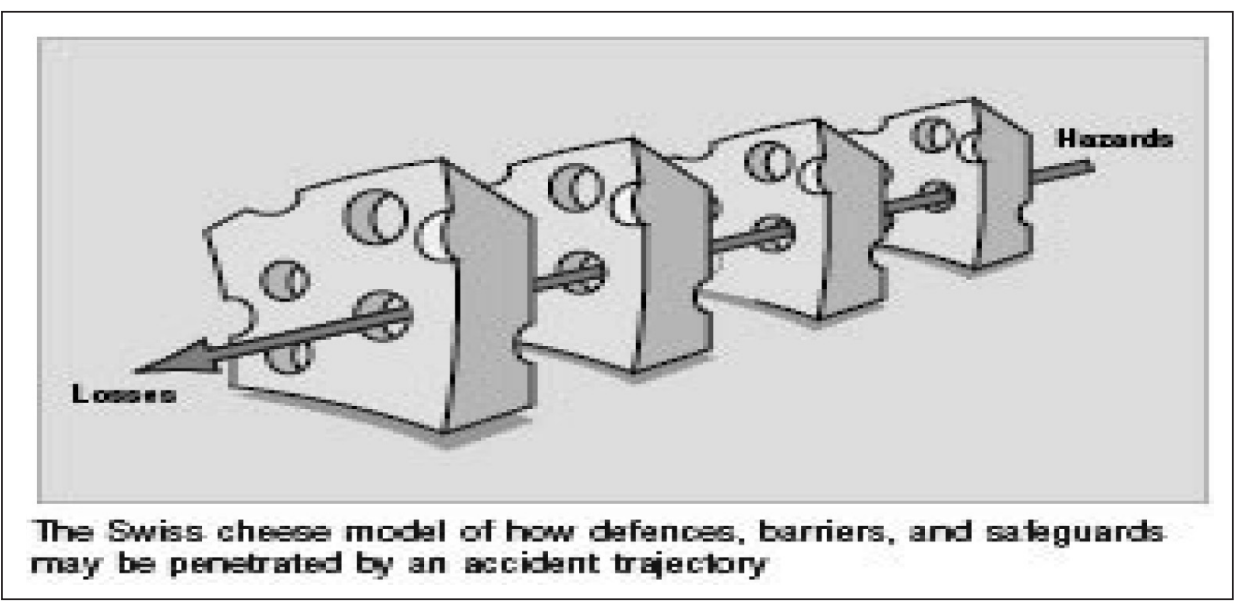

Fonte: British Medical Journal, n. 320, p. 768-770, 2000. 
Os "furos" nas camadas de defesa acontecem em função de erros ativos e de erros latentes. A distinção entre erros ativos e latentes permite a distinção da contribuição humana na ocorrência dos acidentes. "Os erros latentes são "patôgenos residentes" [resident pathogens] inevitáveis dentro do sistema" (REASON, 2000, p. 769) e são gerados por decisões tomadas pelos responsáveis pelo desenho de seu funcionamento e que possibilita a ocorrência de dois tipos de efeitos adversos: (i) efeitos que podem provocar condiçôes (REASON, 2000) que se traduzem em erro no ambiente de trabalho (equipamento inadequado, fadiga, inexperiência) e (ii) que podem criar fragilidades e lacunas no sistema que se mantêm por longos períodos (alarmes e indicadores que não são fidedignos, desenho e construção de processos de trabalho deficientes etc.). Condiçóes latentes podem permanecer imperceptíveis por anos a fio até que se combinem com um erro ativo no sistema de modo a criar uma oportunidade de acidente. Nesse caso, são acidentes de grande monta, tais como: acidentes aéreos, vazamentos em usinas nucleares, etc. Diferentemente do erro ativo, os erros ou condiçôes latentes podem ser remediados e/ou identificados antes que o acidente ocorra. Ao advogar pela abordagem do sistema como forma de prevenir o erro, o autor propóe ações pautadas em distintos objetos: no indivíduo, na equipe, na tarefa, no local de trabalho e na instituição como um todo. A criação e manutenção de um sistema resiliente é o principal objetivo.

A análise do processo de ocorrência do erro dentro do sistema cognitivo, como também da ocorrência de acidentes nos mais diversos ambientes de trabalho, contribui de forma significativa para a prevenção e o desenho de medidas voltadas para a melhoria da segurança, com a consequente diminuição dos riscos. O conhecimento desta matéria é de vital importância para a área da saúde no que diz respeito à formulação de novas estratégias para aperfeiçoamento das várias camadas defensivas do complexo processo de cuidado do paciente dentro do sistema hospitalar. Entretanto, nos parece que as barreiras ou camadas defensivas, mecanismos essenciais introduzidos pelo modelo epidemiológico (CARVALHO, 2008) apresentado por Reason, com as esclarecedoras contribuições trazidas por Runciman e colaboradores no que diz respeito à questão da violação das diretrizes clínicas de higienização de mãos, parecem não trazer respostas a outro tipo de questão mais direcionada às múltiplas correlaçooes existentes entre o ambiente onde o trabalho se realiza, a tarefa a ser executada e seus executores. 
Retomamos neste momento a contribuição trazida por Cohen e outros autores,

citada anteriormente, relativa à importância da distinção entre erro e violação como um caminho para a compreensão dos processos envolvidos na ocorrência do erro. A identificação e compreensão dos atos de violação tomam, então, um papel central nesse contexto, e se transformam no alvo da investigação, em função de esta ser assumida como a etapa inicial de um processo de progressão que culmina na ocorrência de erro médico e possibilita a identificação precoce de situações vulneráveis.

O modelo explicativo de ocorrência do erro trazido pelos autores acima mencionados trabalha na lógica de decomposição das atividades laborais executadas para melhor compreensão das mesmas e propõe como forma de prevenção da ocorrência de erro o enfraquecimento das barreiras ou patógenos residentes inerentes ao sistema, através da criação de camadas defensivas complexas, mas lineares. $\mathrm{Na}$ tentativa de responder à pergunta formulada, relativa aos fatores que estariam envolvidos na escolha inicial que levaria ao afastamento da execução da tarefa conforme a prescrição das normas, sua dinâmica de ocorrência e manutenção da escolha, introduziremos as contribuiçōes teóricas aportadas por Christophe Dejours. Este propõe um modelo sistêmico (CARVALHO, 2008) de compreensão das açôes e tarefas executadas pelo indivíduo para a consecução das atividades profissionais dentro do contexto laboral, que leva em conta essas múltiplas inserções envolvidas e cuja compreensão se dá no microcosmo onde trabalho é realizado.

\section{O erro como fator inerente à execução da tarefa}

Christophe Dejours (2005), diretor do Laboratório de Psicologia do Trabalho do Conservatório Nacional de Artes e Ofícios de Paris, analisa como a rapidez e a complexidade das transformaçôes contemporâneas do trabalho tornaram ultrapassado o conhecimento científico armazenado e compartimentado em diferentes disciplinas. A complexificação das organizações de trabalho, por uma questão de ordem prática, passa a precisar de pessoas permanentemente motivadas e preparadas para enfrentar e superar imprevistos. Para tal, é necessário garantir que haja condiçôes sociais e psicoafetivas favoráveis à mobilização das inteligências que irão se defrontar com situações imprevistas.

Também ergonomista, Dejours utilizou os achados dos estudos em ergonomia realizados na França a partir da segunda metade do século XX, que possibilitaram 
a construção de um dos conceitos centrais em sua teoria: o trabalho real. Esse que contrasta e se opõe ao "trabalho prescrito, é aquilo que no mundo se faz conhecer por sua resistência ao domínio técnico e ao conhecimento científico” (DEJOURS, 2005, p. 40). Ou seja, o trabalho real é tudo aquilo que na realização da tarefa não pode ser obtido pela observação rigorosa das leis, normas e regras técnicas existentes para execução da mesma, isto é, o trabalho prescrito. O trabalho real incide sobre a dimensão humana, no que diz respeito ao que deve ser rearranjado, imaginado, inventado, acrescentado pelos envolvidos em levar em conta e dar conta do real do trabalho. O real (do trabalho), para Dejours, está intrinsecamente ligado ao fracasso, visto que a organização do trabalho apresenta inúmeras contradições e não é completamente absorvida por aqueles que a executam. A execução de tarefas torna-se então um enigma a decifrar, já que o prescrito (do trabalho) nunca é suficiente. O real é a parte da realidade que resiste à simbolização e não remete exclusivamente à materialidade físicoquímico-biológica no mundo.

A técnica passa a ser um ato que incide sobre o real, e que tem em sua origem os traços da cultura onde ela é desenvolvida e é sancionada a partir do julgamento daqueles envolvidos - o outro - mas que ao mesmo tempo produz cultura, dando resposta às exigências da uma sociedade historicamente datada. O trabalho é uma atividade julgada e reconhecida pelo outro, não somente por sua eficácia técnica, mas por sua utilidade social e econômica. Para Dejours, é no trabalho (real) que "os limites do saber, do conhecimento e da concepção, (...) se chocam com os atos técnicos e as atividades de trabalho" (DEJOURS, 2005, p. 43). E mais ainda: “Todo trabalho é sempre trabalho de concepção. A definição de trabalho corrente insiste na dimensão humana do trabalho. O trabalho é, por definição, humano, uma vez que é mobilizado justamente ali onde a ordem tecnológica-maquinal é insuficiente" (LANCMAN; SZNELWAR, 2005, p. 65). As interações entre o sujeito - o ego -, e o outro estão submetidas a uma exigência suplementar, a coordenação das atividades no trabalho.

O triângulo tecnológico do trabalho (figura 2) cujos vértices são o real, o ego e o outro, criado por Dejours, nos fala das interações entre o sujeito que trabalha e aqueles que compartilham do mesmo contexto laboral - o ego e o outro. Essas interações estão submetidas às exigências da coordenação das atividades, que 
por sua vez remetem à tradição. A tradição nesse contexto é uma condição sobre a possibilidade de coordenação, não estando assegurada unicamente pelo cognitivo-instrumental, mas supõe também relações e interações no registro da compreensão e do sentido, bem como relações sociais de trabalho. $\mathrm{O}$ triângulo tecnológico, portanto, é atravessado pelo ato na relação entre o ego e o real, pela tradição na relação entre o ego e o outro e pela eficácia na relação o real e o outro. $\mathrm{O}$ ato, seja qual for o instrumento de que faz uso, se propõe a uma mudança no mundo real. Para um ato ser considerado um ato técnico, necessita da homologação de um grupo de sujeitos capacitados para julgar se há continuidade ou ruptura do mesmo em relação à tradição, que é uma forma de sedimentação das rotinas praticadas até então. $\mathrm{O}$ ato técnico, após ser considerado como tal, e consequentemente, passar a fazer parte da tradição, contribui para que a própria tradição se torne renovada. A eficácia, neste sentido, é a capacidade que o ato técnico tem de transformar o mundo real. A eficácia não existe em si, ela passa por um julgamento. E esse julgamento tem como fundamento ser uma atribuição do outro ao qual o ego está ligado pela tradição. A complexidade desse processo faz-nos entrever que é impossível prever-se tudo e ter-se o domínio sobre tudo de forma antecipada no trabalho, portanto a falha humana frente à tarefa, no trabalho real, é inevitável.

\section{Figura 2 - Triângulo Tecnológico}

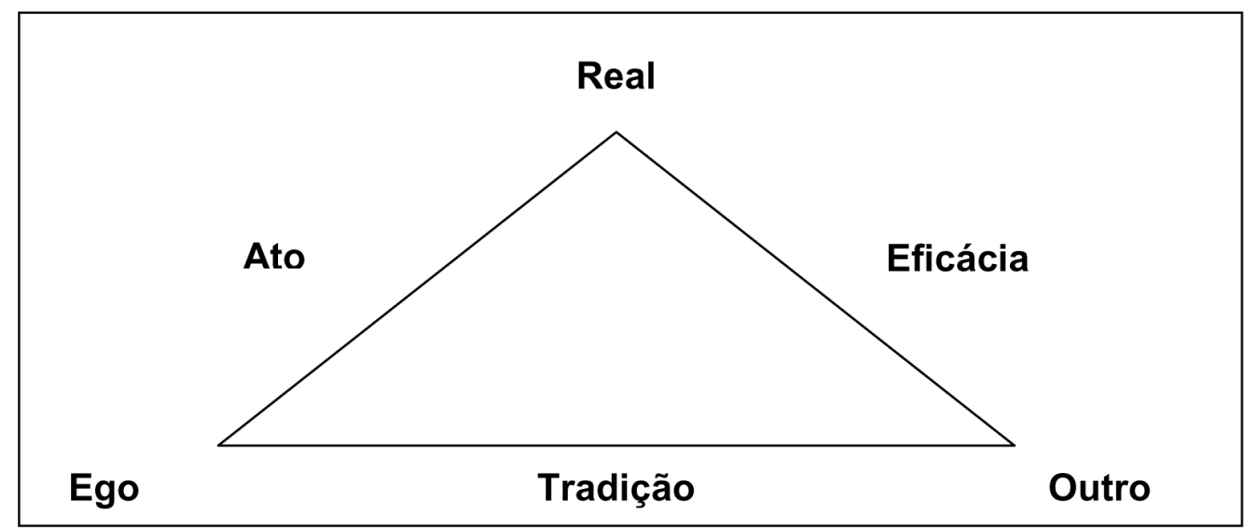

Fonte: Dejours (2007, p. 37). 
A distância entre a organização do trabalho prescrito e o trabalho realé dinâmica. Em alguns momentos oferece margens para a liberdade criadora aos sujeitos envolvidos na execução da tarefa. Em outros momentos é restritiva, fazendo com que esses mesmos sujeitos temam ser surpreendidos cometendo erros. É comum que esses dois processos, tanto de liberdade criadora como de restrição à tarefa de liberdade criadora e de restrição frente a tarefa, ocorram concomitantemente (LANCMAN; SZNELWAR, 2004). Esse espaço de manobra entre a organização do trabalho prescrito e o trabalho real possibilita, através da inteligência astuciosa, que seja possível ao trabalhador lidar com os reveses do real de forma criativa e transformá-los, incluindo-os no repertório das ações prescritas. Processos, caso sejamos astuciosos, que se realizarão infinitamente.

Portanto, a inteligência astuciosa ou inteligência prática é a disponibilidade de iniciativa, criatividade e de formas de inteligência específicas próximas daquilo que o senso comum denomina de engenhosidade, capazes de ajustar a tarefa real à organização prescrita do trabalho. Ela advém fundamentalmente do engajamento do corpo na execução da tarefa, ou seja, manejos e maneirismos do corpo se ajustando ao que a tarefa propõe e demanda. Privilegia a habilidade em detrimento da força numa tentativa do uso econômico de forças.

O processo de utilização da inteligência astuciosa possui paradoxos pelo fato de comportar dois lados. O primeiro deles é que a astúcia em relação ao real (do trabalho) ao introduzir a imaginação criadora, a invenção e certa falta de prescrição - quebra galho -, implica digressão à norma e a tradição. O segundo aspecto e que está relacionado ao espaço privativo, local onde se realizam estas ações - bricolagens, tentativas e ensaios -, isto é, ao abrigo dos controles e da segurança, no segredo.

O segredo confere poder a quem o detém, pois o coloca em posição vantajosa de negociação na esfera social e econômica em relação aos colegas e superiores, mas há reveses nesta questão. Primeiramente, o segredo é visto como desvio da disciplina. O outro aspecto é o fato de lançar o sujeito na solidão e, consequentemente, na dissimulação em relação à execução da tarefa. O quebra-galho no coletivo do trabalho arrisca criar incoerência e desorganizar a coordenação das atividades e dos indivíduos, isto é, desordenar aquilo que geralmente todos têm uma consciência clara. Para vencer os inconvenientes do segredo, deve-se recorrer 
à visibilidade (DEJOURS, 2007). Portanto, as descobertas, engenhosidades e inovações advindas das interpretações da organização prescrita do trabalho devem ser coordenadas, para não se incorrer no risco de provocarem incoerências e incompreensões que destruiriam as potenciais vantagens da inteligência prática, tendo em vista a qualidade e segurança do trabalho.

A visibilidade é, então, a condição de passagem do estatuto subjetivo de engenhosidade à objetivação dos achados. Ela pode se dar entre colegas que executam o mesmo tipo de tarefa - eixo horizontal - e aqueles que se encontram na escala hierárquica - eixo vertical. As condições que tornam possível a visibilidade é a confiança entre as pessoas, pensada a partir da intersubjetividade e das interações no coletivo de trabalho.

A confiança, que diz respeito à promessa de equidade nos julgamentos proferidos pelo outro sobre a conduta do ego, é o requisito da visibilidade e também condição precípua à coordenação e cooperação. A confiança possui também papel determinante no processo apontado por Dejours (LANCMAN; SZNELWAR, 2004) como o triângulo dinâmico do trabalho (figura 3), onde se dão as dinâmicas e inter-relações entre o trabalho, o sofrimento e o reconhecimento inerentes à execução da tarefa no real (do trabalho).

\section{Figurra 3 - Triângullo Dinâmico do Traballho}

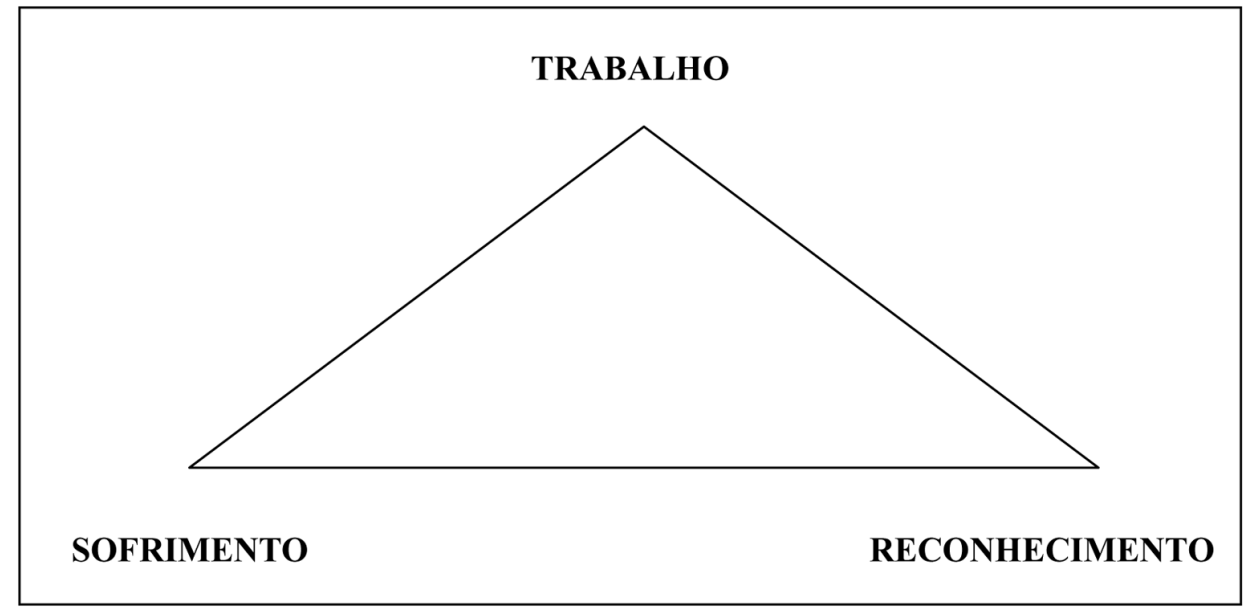

Fonte: Lancman e Sznelwar (2004, p. 74). 
Os julgamentos, nos quais a confiança tem sua base de sustentação, dizem respeito às dificuldades práticas encontradas face ao real, como resistência e revés à tarefa a ser executada e a qualidade dos arranjos produzidos graças à engenhosidade. Esses julgamentos se dão sob duas óticas: utilidade e beleza. $\mathrm{O}$ primeiro está relacionado à utilidade técnica ou econômica da atividade singular do ego e confere ao ato técnico sua inscriçãa na esfera do trabalho. $\mathrm{O}$ segundo possui duas faces. A primeira está relacionada a conformidade do trabalho ou serviço com as artes do ofício e confere ao ego, no sentido qualitativo, o pertencimento ao coletivo ou à comunidade de pertença. $\mathrm{O}$ segundo, mais comum, mas mais importante, consiste em apreciar o que faz a distinção, especificidade ou até mesmo o estilo de trabalho. Tal julgamento confere ao ego o reconhecimento de sua identidade singular dentro de um coletivo de iguais e o julgamento é essencialmente proferido pelos pares.

O reconhecimento é uma forma específica da retribuição moral-simbólica dada ao ego como forma de compensação pela eficácia da organização do trabalho, isto é, engajamento de sua subjetividade e inteligência. Para que a cooperação se dê, além de todo esse processo, é necessário que ocorra a etapa de arbitragem, ou seja, colocar os achados técnicos à prova de discussão, das vantagens e inconvenientes de sua adoção, posteriormente estabilizá-los ou integrá-los à tradição da empresa ou do ofício. O reconhecimento e o processo nele envolvido possibilitam a evolução das regras do trabalho que estão numa relação dialética com a organização do trabalho prescrito, que por elas são subvertidas, para então melhorá-las. A cooperação, enfim, situa-nos no nível do par tarefa-atividade, ou seja, no nível da inteligência singular.

Trabalhar, como dito anteriormente, não é somente executar atos técnicos, é também fazer funcionar o tecido social e as dinâmicas intersubjetivas indispensáveis à psicodinâmica do reconhecimento, caráter necessário à mobilização subjetiva da personalidade e inteligência. Mais ainda, o fator humano não pode ser reduzido à dimensão técnico-científica e nem à psicológica, ela também envolve posições ideológicas e escolhas éticas dos indivíduos que trabalham e intervêm no espaço de discussão (DEJOURS, 2005).

A psicodinâmica do reconhecimento tem papel fundamental no destino do sofrimento no trabalho, sofrimento este advindo de dificuldades práticas 
encontradas face ao real, e na possibilidade de transformar sofrimento em prazer.

Em síntese, o triângulo da psicodinâmica do trabalho nos aponta que o acesso ao reconhecimento é feito pela via do sofrimento no trabalho, que por sua vez é proveniente de toda a situação laboral onde o ego se encontra diante de vários constrangimentos. A construção de sentido no ato da execução da tarefa pode transformar sofrimento em prazer. A subjetividade, então, é substituída pela identidade singular na esfera do trabalho, que possibilita enfrentar os ataques direcionados a saúde mental. A conquista da identidade está especialmente relacionada à realização no campo das relações sociais, que por sua vez favorece a construção da identidade em outros campos da vida subjetiva. Fechando o triângulo dinâmico, a conquista da identidade no campo social, mediada pela atividade do trabalho, passa pela dinâmica do reconhecimento, que por sua vez gera a mobilização da racionalidade subjetiva frente ao sofrimento.

Mas, em realidade, o reconhecimento raramente é satisfatório. Espera-se então, que o sofrimento no trabalho gere uma série de manifestações psicopatológicas. Se o sofrimento não se faz acompanhar por descompensações psicopatológicas é porque contra ele os sujeitos empregam defesas que lhe permitem controlá-lo. Além das estratégias de defesa individuais descritas pela psicanálise, existem as coletivas (DEJOURS, 1987, 1999, 2005, 2007; LANCMAN; SZNELWAR, 2004). As defesas coletivas dos trabalhadores são especificamente marcadas pelas pressões reais do trabalho relacionadas às especificidades de cada contexto profissional e o funcionamento destas estratégias mostra que elas podem igualmente contribuir para tornar aceitável aquilo que não deveria sê-lo. As defesas cumprem um papel paradoxal, porém capital. Necessárias à proteção da saúde mental contra os efeitos deletérios do sofrimento,

as estratégias defensivas também podem funcionar como armadilha que insensibiliza
contra aquilo que faz sofrer. Permite às vezes tornar tolerável o sofrimento ético, aque-
le que pode experimentar ao cometer, por causa do seu trabalho, atos que condena
moralmente. (DEJOURS C, 2007, p. 38 ).

Ou seja, infligir a outrem um "sofrimento indevido", que pode causar sofrimento àquele que assim age, mas também serem construídas defesas contra este sofrimento para manter o equilíbrio psíquico. 


\section{Considerações finais}

Os modelos explicativos para a compreensão da consecução do erro ou violação na execução das tarefas no ambiente laboral, acima explicitados, trazem inúmeras contribuições teóricas passíveis de aplicação direta à prática, algumas delas já implementadas. A análise do processo de ocorrência do erro dentro do sistema cognitivo, introduzida por James Reason, contribui e parece ter seu foco de ação voltado para a prevenção e o desenho de medidas direcionadas à segurança e à diminuição de riscos, propiciando na área de saúde a criação de estratégias nas várias camadas defensivas no complexo processo de cuidado ao paciente que se encontra em tratamento dentro sistema hospitalar. Já as contribuições de Christophe Dejours se voltam para a análise da dinâmica do contexto laboral, microcosmo onde o trabalho ocorre e que envolve o indivíduo, a tarefa a ser executada e o conjunto dos profissionais que dela participam, direta ou indiretamente, pertencendo ou não a mesma categoria profissional e nível hierárquico.

Runciman e colaboradores, ao fazerem clara distinção entre erro e violação, nos aproximam mais, no nível conceitual e teórico, da questão da baixa adesão dos profissionais de saúde aos procedimentos de higienização das mãos, em especial os médicos. A detecção do elemento de escolha com relação às ações a serem realizadas pelos indivíduos no que diz respeito ao desvio ou fuga às normas prescritas, ou seja, a ação da violação, possibilita a criação de instrumentos para observação e análise dos processos em curso.

Tanto Dejours quanto Runciman e colaboradores dão destaque à necessidade de se "aparar as arestas" ou realizar "quebra-galhos" no cotidiano da execução das tarefas laborativas, no sentido de levar a termo uma determinada atividade ou tarefa proposta. Runciman sugere que esse fato contribui de maneira significativa para a ocorrência da violação. Dejours parece avançar nesta questão ao partir do referencial de que a realização da tarefa não pode ser obtida somente pela observação rigorosa das leis, normas e regras técnicas existentes, ou seja, o trabalho real. $\mathrm{O}$ "aparar de arestas" e o "quebra galho", para Dejours, possuem dupla faceta. Por um lado, colocam em risco a consecução da tarefa e tudo aquilo que a envolve, por provocarem incoerências e incompreensões, e nesse aspecto podemos talvez utilizar a baixa adesão às normas e procedimentos de Higienização de Mãos como exemplo paradigmático. Por outro, como nos aponta o autor, o "aparar de arestas” 
e o "quebra galho" possibilitam o surgimento da criatividade no indivíduo diante das dificuldades e impasses no cotidiano do trabalho, podendo gerar soluçóes mediante a visibilidade e o consequente julgamento realizado pelos seus pares.

Baseado nessa assertiva, ainda no que diz respeito à Higienização de Mãos, inferimos que propiciar a visibilidade do processo que subjaz as ações de baixa adesão pode descortinar possibilidades de lidar de forma criativa com os "reveses" do real do trabalho e diminuir o sofrimento dele advindo. Mais ainda, ao utilizar o potencial desse coletivo de profissionais no enfrentamento de um impasse vivido no cotidiano das tarefas, se reforçaria a capacidade de julgamento desse mesmo coletivo e se valorizaria a capacidade de criação desses indivíduos, mesmo dentro das limitações que as diretrizes técnicas, advindas do avanço tecnológico, trazem.

Os fatores emocionais, além de outros fatores menos distintos, apontados por Reason como determinantes na passagem do nivel baseado nas normas para o nivel baseado no conhecimento, ou seja, quando a utilização das normas existentes para solução do problema, apesar de inúmeras tentativas, não encontram sucesso, parecem encontrar uma perspectiva de maior compreensão através do aspecto criativo do "quebra-galho", como também do tratamento conceitual de trabalho proposto por Dejours, no qual é percebido como eminentemente humano, um ato de concepção e de mobilização para o qual a ordem tecnológico-maquinal é insuficiente.

Por último, reiteramos a contribuição teórica trazida por Dejours, no que diz respeito aos mecanismos de defesa coletivos na possibilidade de compreensão da passividade e do alheamento dos profissionais de saúde em relação às evidências referentes aos procedimentos de higienização das mãos. O papel paradoxal desses mecanismos na dinâmica do contexto laboral, que protegem os profissionais de saúde dos efeitos deletérios do sofrimento, mas podem também insensibilizá-los contra aquilo que faz sofrer, poderá propiciar a identificação dos fatores que se encontram em jogo e que incidem diretamente sobre a segurança do paciente.

\section{Referências}

BEGGS, C. et al. The influence of nurse cohorting on hand hygiene effectiveness. American journal of infection control, v. 34, n. 10, p. 621-626, 2006.

CARVAlHO, P V R. Acidentes em sistemas complexos [apresentação Power Point]. Congresso Safety, 2008. 
CHALMERS, Straub. Standard principles for preventing and controlling infection. Nursing standard, v. 20, n. 23, p. 57-65, 2006.

COHEN, T. et al. Reevaluating recovery: perceived violations and preemptive interventions on emergency psychiatrics rounds. J Am med inform assoc, v. 14, n. 3, p. 312-319, 2007.

DEJOURS, C. A banalização da injustiça social. 7 ed. Rio de Janeiro: FGV, 2007, 160 p.

DEJOURS, C. A loucura do trabalho. São Paulo: Oboré, 1987, 163 p.

DEJOURS C. Conferências brasileiras. Identidade, reconhecimento e transgressão no trabalho. São Paulo: Fundap, 1999. 180 p.

DEJOURS C. O fator humano. 5. ed. Rio de Janeiro: FGV, 2005. 104 p.

GUIDELINES on Hand Hygiene in Health Care (advanced draft). World Alliance, WHO, p. 8-10, 2006.

HUGONNET, S.; PITTET, D. Hand Hygiene - Beliefs or Science? European Society of Clinical Microbiology and Infectious Diseases. Clin microbiol infect, n. 6, p. 348-354, 2000.

KOHN, L.T.; KORRIGAN, J.M.; DONALDSON, M.S. To err is human: building a safer health system. Washington D.C.: National Academy Press, 2000. 311 p.

LANCMAN, S.; SZNELWAR, LI. (Org.). Christophe Dejours: da psicopatologia do trabalho à psicodinâmica do trabalho. Rio de Janeiro: Fiocruz, 2004, 346 p.

MERRY, A.; SEDDON, M. Quality improvement in healthcare in New Zealand. Part 2: are our patients safe and what are we doing about it? $N$ Zeal med J, v. 119, n. 1.238, p. $\mathrm{U}-2.111,2006$.

MORET, L.; TEQUI, B.; LOMBRAIL, P. Should self-assessment methods be used to measure compliance with handwashing recommendations? A study carried out in a French university hospital. American journal of infection control, v. 32, n. 7, p. 384-390, 2004.

PITTET, D. Complaince with hand desinfection and its impact on hospital-acquired infections. Jornal of hospital infection, v. 48, suppl. A, p. S40-S46, 2001 b.

PITTET D. Improving adherence to hand hygiene practice: a multidisciplinary approach. Emerging infectious disease, v. 7, n. 2, p. 234-240, 2001a.

RASMUSSEN J. Information processing and human-machine interaction. Amsterdam: North-Holland, 1986. 256 p.

REASON J. Human error. London: Cambridge University Press, 2003, 302 p.

REASON J. Human error: models and management. Brit med j, n. 320, p. 768-770, 2000.

RUNCIMAN, B.; MERRY, A.; WALTON, M. Safety and ethics in healthcare: a guide to getting it right. London: British Library, 2007, p. 109-134. 
Medical errors and violation of rules and standards in health: a theoretical discussion in the area of patient safety

In 1999, the report by the Institute of Medicine (IOM), pointed that there are significant adverse events and that more than half of these occurrences were caused by medical errors, provoking numerous actions and research on Patient Safety. Infections related to health care (IRAS), one of the problems faced in the area, are the subject of research that attempt to create procedures and strategies to prevent such events. Hand hygiene, because it is the simplest measure of control in IRAs and, paradoxically, the one with the lowest compliance rate among physicians, is the target of numerous programs and campaigns. The need to reverse this state has generated extensive literature that, among other things, indicates and identifies barriers and risk factors for poor adherence to standards and procedures for hands hygiene, but also seeks to understand the behavioral aspects concerned. This paper presents some theoretical models aimed at understanding the behavioral dynamics which involves the achievement of error and violation and carries out an analysis with the possibilities of apprehension of the process. Finally, it is considered that the explanatory models jointly presented bring contributions that can be applied in practice and that identifying and understanding the mechanisms of collective defense would lead to factors that are at stake in the low adherence to procedures, sanitation of hands among physicians, despite the existing evidence.

> Key words: patient safety, medical error, violation. 